\title{
Perfil das Atividades Complementares dos Graduandos em Medicina pela Universidade Estadual de Feira de Santana, 2009-2017
}

\author{
Profile of Complementary Activities of \\ Last-Year Medical Students at the State \\ University of Feira de Santana, 2009-2017
}

Marcelo Leandro Santana Cruz Marcelo Torres Peixoto Carlos Alberto Lima da Silva

Wanessa Galvão Damas ${ }^{1}$

Ana Beatriz Menezes de Oliveiral

\section{PALAVRAS-CHAVE}

- Educação Médica.

- Currículo.

- Atividades Extracurriculares. 


\section{KEY-WORDS}

- Medical Education.

- Curriculum.

- Extracurricular Activities.

Recebido em 20/7/19

Aceito em 11/8/19

\begin{abstract}
Complementary Activitiesaimatenriching theteaching-learning process, favoring the complementation of social and professional formation, being carried out through academic-scientific-cultural activities, of which objective is to improve the academic training. This article aims to characterize the profile of the complementary activities carried out by last-year medical students from Feira de Santana State University (UEFS), from 2009 to 2017. This was a cross-sectional, retrospective and descriptive study. Data collection was carried out by reviewing the data contained in the opinions of the course collegiate and certificates delivered by the students. Subsequently, the data were processed using the software Statistical Package for the Social Sciences (SPSS), version 20.0 for Windows, and presented as charts and tables, with subsequent descriptive analysis of the variables of interest. The sample consisted of 171 students, with a predominance of females $(56,1 \%)$; most of the activities performed by the students took place as participation in scientific events (51,6\%); it was observed that cultural and sports activities are not used by the collegiate. The most sought after extracurricular trainings were in the urgency and emergency area (38.5\%); there was an average of 0.93 articles published per student, with Pediatrics being the area with the highest number of publications (24,8\%). Moreover, there was a great disparity between the students' course load and the hours utilized by the course collegiate, with losses of $74 \%$ in the extracurricular training activities and $63 \%$ in monitoring + scientific initiation + extension activities. The results of this study point to the need to discuss and revise the Complementary Activities Regulations of the UEFS medical course, and may contribute to medical education, for discussing a topic disregarded by most undergraduate medical courses.
\end{abstract}

\footnotetext{
Aceito em 11/8/19
}

\section{INTRODUÇÃO}

O processo de formação profissional é essencial para o desenvolvimento e a manutenção do Sistema Único de Saúde (SUS) como um modelo nacional, público, universal, equitativo, integral e com participação popular ${ }^{1}$. É no período de formação que o futuro médico irá adquirir conhecimentos, competências, habilidades e valores que o acompanharão durante toda a vida profissional. Atualmente, o processo de formação dos profissionais de saúde de nível superior vivencia mudanças que causam impactos diretos e indiretos nos sistemas de saúde em todo o mundo, inclusive no Brasil ${ }^{1}$.

Com o objetivo de reorientar a formação médica no Brasil, em 2001, o Ministério da Educação (MEC) publica as Diretrizes Curriculares Nacionais (DCN) ${ }^{2}$, definindo os princípios, fundamentos, condições e procedimentos da formação médica a serem aplicados em âmbito nacional na organização, desenvolvimento e avaliação dos currículos e projetos pedagógicos dos cursos de graduação em Medicina. Esse documento propõe a adoção de metodologias ativas no processo de ensino-aprendizagem, contribuindo com a autonomia do estudante, e também privilegia novos cenários de aprendizado, como a Atenção Básica em Saúde (ABS).
Em 2014, as DCN foram atualizadas, estabelecendo a necessidade de articulação entre conhecimentos, habilidades e atitudes em três áreas específicas: atenção, gestão e educação em saúde. $O$ futuro médico deve, na atenção, elaborar projetos terapêuticos, respeitando a diversidade biológica, subjetiva, étnico-racial, de gênero, orientação sexual, socioeconômica, política, ambiental, cultural e ética. Na gestão, deve ser capaz de compreender os princípios, diretrizes e políticas do sistema de saúde e participar de ações de planejamento, gerenciamento e administração. Na educação, deve ser responsável pela própria formação inicial, continuada e em serviço ${ }^{3}$.

As DCN priorizam a aprendizagem centrada no estudante, que tem papel ativo em seu processo de formação, sendo incentivado a pensar, refletir, discutir, analisar e agir sobre as temáticas e os conteúdos pertinentes à formação médica, relacionando-os com a realidade em que está inserido. Também é estimulada a autonomia do aluno na busca pelo conhecimento, quer seja no ambiente universitário, no mundo virtual, utilizando as novas tecnologias de comunicação, ou no ambiente fora dos muros acadêmicos, em atividades de pesquisa, extensão, estágio, esportivas e culturais. 
Alguns autores ${ }^{4-9}$ investigaram as atividades extracurriculares e/ou o currículo paralelo/oculto dos graduandos em Medicina. Tais estudos sinalizam que existem subjetividades, singularidades e intencionalidades individuais e coletivas envolvidas no processo de busca pela complementação da formação médica em ambientes fora da universidade. Segundo esses autores, os estudantes fazem suas escolhas motivados por diversas questões, como preencher lacunas do conhecimento, ampliar os saberes e práticas em determinada especialidade, conhecer a realidade do mercado de trabalho ou desenvolver atividades de pesquisa e extensão.

Para o MEC, as atividades complementares têm a finalidade de enriquecer o processo de ensino-aprendizagem, privilegiando a complementação da formação social e profissional, devendo ser realizadas com flexibilidade de carga horária, não excedendo $20 \%$ do total do curso. São exemplos de atividades complementares: participação em eventos internos e externos à instituição de educação superior, como semanas acadêmicas, congressos, seminários, palestras, conferências e atividades culturais; integralização de cursos de extensão e/ou atualização acadêmica e profissional; atividades de iniciação científica, extensão e monitoria ${ }^{10,11}$.

O curso de Medicina da Universidade Estadual de Feira de Santana (UEFS) foi implantado em 2003, e seu projeto político pedagógico ${ }^{12}$ vislumbra a formação de um médico generalista, engajado nos territórios sociais, onde emergem os problemas e necessidades locais do SUS, com eixos de visão humanista e aderência às políticas de saúde do País. Adota metodologias ativas no processo ensino-aprendizagem, mais especificamente a Aprendizagem Baseada em Problemas (APB) e a Metodologia da Problematização. Desta forma, prioriza a aprendizagem centrada no estudante, que tem papel ativo em seu processo de formação.

Em seu Regimento das Atividades Complementares ${ }^{13}$, o curso de Medicina da UEFS compreende estas atividades como acadêmico-científico-culturais, com o objetivo de aprimorar a formação, fomentando o tripé ensino-pesquisa-extensão, propiciando o desenvolvimento do raciocínio lógico, o estímulo à participação em projetos de iniciação científica e o desenvolvimento de suas habilidades e competências. $\mathrm{O}$ estudante deve cumprir carga horária mínima de 490 horas ao longo dos seis anos do curso.

Este estudo teve como objetivo caracterizar o perfil das atividades complementares realizadas pelos graduandos do curso de Medicina da Universidade Estadual de Feira de Santana no período de 2009 a 2017.

\section{METODOLOGIA}

Utilizou-se neste estudo a pesquisa documental de natureza descritiva, cujo campo de estudo foi o curso de graduação em Medicina da UEFS, localizada no semiárido baiano. Desde a sua implantação, em 2003, até o ano de 2017, o curso já formou 279 médicos, e todos eles cumpriram no mínimo 490 horas de atividades complementares, comprovadas por meio da emissão de parecer pela comissão de avaliação do curso (Quadro 1), com cópias dos certificados entregues.

Inicialmente, buscou-se computar toda a população de egressos, porém não foram localizados os certificados referentes aos formandos dos anos 2012, 2014 e 2015, ocasionando uma perda de $38,7 \%(\mathrm{n}=108)$ dos indivíduos, ficando a amostra final do estudo com 171 participantes. Esta perda limitou a construção de uma série temporal, visto que perdemos as turmas centrais da série. Contudo, os dados coletados nos permitiram identificar as tendências de evolução das atividades complementares.

Cada egresso possuía uma pasta individual que continha o parecer da comissão de avaliação e as cópias dos certificados. Para a coleta de dados, as pastas individuais foram separadas por ano de conclusão, e, posteriormente, os certificados foram organizados por categoria de atividade, conforme discriminado no Regimento das Atividades Complementares de Graduação em Medicina ${ }^{13}$.

As categorias de atividade deram origem às seguintes variáveis: monitoria + iniciação científica + extensão, publicação de artigo, apresentação em eventos científicos, participação em eventos científicos, organização de eventos científicos, estágio extracurricular, participação em ligas acadêmicas, representação de série, cursos de idiomas, membro da Osce (Objective Structured Clinical Examination) e módulo de Humanidades. Também discriminamos as variáveis segundo as especialidades médicas, conforme a Resolução do Conselho Federal de Medicina (CFM) no 1.666/2003 ${ }^{14}$ e a tabela de áreas do conhecimento da Coordenação de Aperfeiçoamento de Pessoal de Nível Superior (Capes) ${ }^{15}$.

As informações constantes nos pareceres e certificados foram registradas num banco de dados utilizando-se o software SPSS (Statistical Package for Social Science, versão 20.0 para Windows), sendo realizada a análise descritiva das variáveis de interesse.

Este estudo é um recorte do projeto "Formação médica na Atenção Primária à Saúde nos cursos de graduação em Medicina da Bahia, Brasil", aprovado pelo Comitê de Ética em Pesquisa da UEFS pela CAAE: 70651117.1.0000.0053, sendo respeitadas as Resoluções 466/12 e 510/16 do Conselho Nacional de Saúde. 


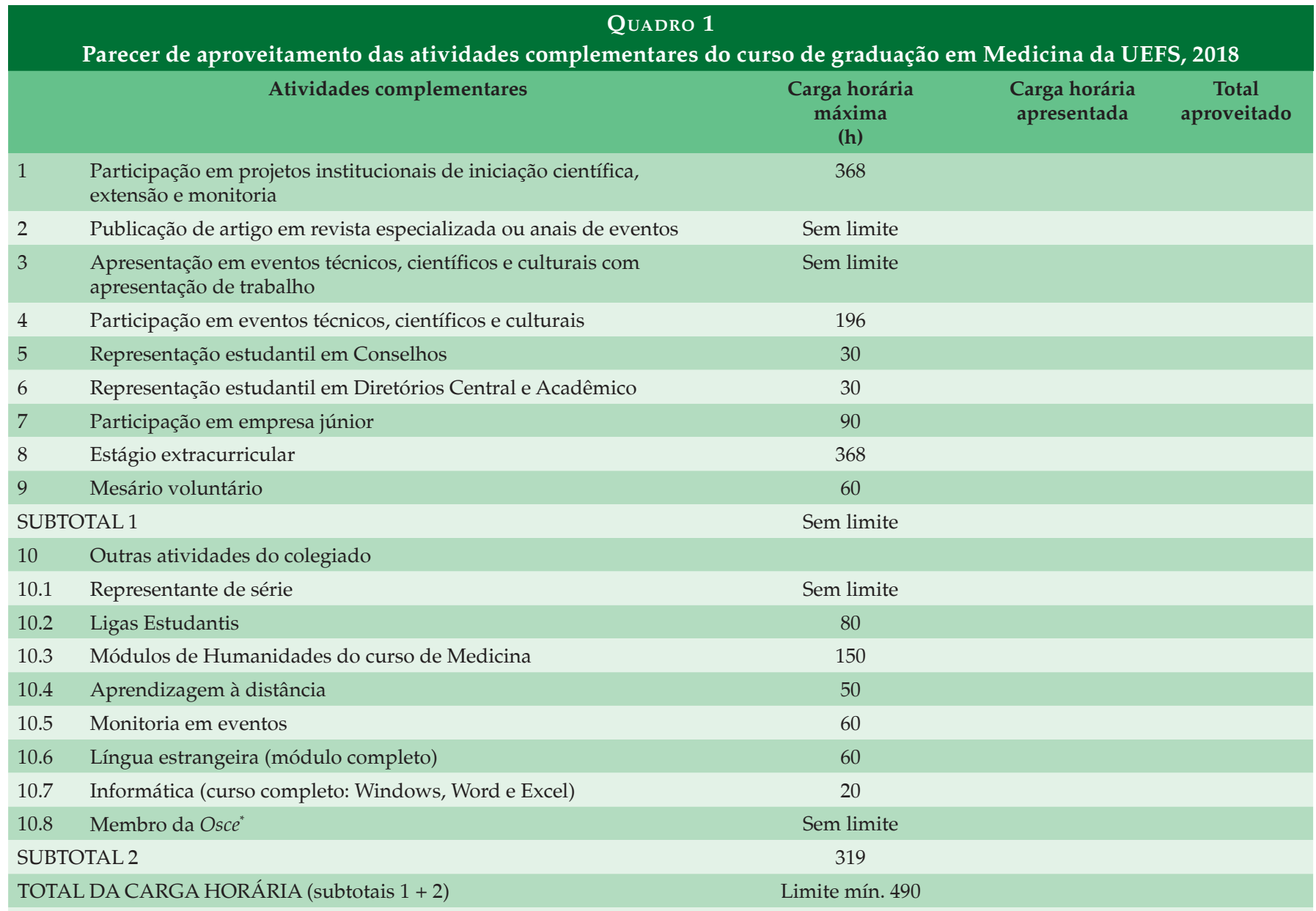

PARECER: aluno(a)

( ) cumpriu ( ) não cumpriu a carga horária mínima de $490 \mathrm{~h}$ de atividades complementares.

Feira de Santana,

Nome do parecerista:

Assinatura do parecerista:

Objective Structured Clinical Examination

\section{RESULTADOS E DISCUSSÃO}

$\mathrm{Na}$ amostra composta por pareceres de 171 estudantes que preencheram os critérios de inclusão, observou-se prevalência do sexo feminino $56,1 \%$ ( $\mathrm{n}=96$ ) em comparação ao masculino, com $43,9 \%(n=75)$. A predominância do sexo feminino nos cursos de Medicina é comumente observada em estudos recentes, o que corrobora o cenário de emancipação e empoderamento feminino. Haddad et al. ${ }^{16}$, avaliando o perfil da formação médica brasileira no período de 1991 a 2008, evidenciaram a predominância de estudantes do gênero feminino (55\%). Ainda, o Censo da Educação Superior referente a 2016 mostra que aproximadamente $56 \%$ dos estudantes matriculados nos cursos de graduação em Medicina são mulheres ${ }^{17}$.
Em estudo realizado na Universidade Federal do Rio Grande do Sul, Zimmer et al. ${ }^{18}$ observaram que $93,9 \%$ dos estudantes de Medicina acreditavam ser necessária alguma atividade extracurricular para complementar a formação. Tavares et al. ${ }^{5}$, ao estudarem a tradição dos estágios extracurriculares na formação médica no Brasil, identificaram que os motivos mais valorizados pelos estudantes para ingressar nessas atividades são fatores culturais da instituição, aspectos relacionados a docentes e a serviços de referência, e relevância da atividade para aprimorar o currículo e concursos de residência médica. A necessidade de ampliar as atividades práticas na formação é apontada por Taquette et al. ${ }^{19}$, cuja pesquisa revelou que $88,9 \%$ dos participantes identificavam como causa 
mais frequente das atividades extracurriculares o aperfeiçoamento prático.

Ao analisar as atividades complementares dos egressos da UEFS (Tabela 1), verifica-se que as três primeiras categorias estão associadas a eventos científicos, sendo que 51,6\% ( $n=3.311)$ dos certificados foram de participação em eventos, $12,5 \%(n=801)$ de apresentação em eventos e 7,7\% (n = 495) de organização de eventos. No total, $71,8 \%(n=4.607)$ dos certificados apresentados remetiam a eventos científicos de abrangência local, regional ou nacional. Este resultado demonstra a preocupação discente com a atualização científica e o preenchimento de lacunas na formação. Esses eventos científicos também são uma oportunidade de conhecer outras cidades e de ter contato com estudantes de diversos cursos, o que favorece conhecer outras realidades científicas e culturais, enriquecendo a formação do futuro médico e da futura médica. Outra vantagem dessa modalidade é a aquisição de carga horária em um curto período de tempo, muitas vezes durante o fim de semana, não interferindo nas atividades curriculares obrigatórias. Porém, essa grande concentração em um único lócus de atividade é preocupante, pois os estudantes perdem a oportunidade de vivenciar outras experiências importantes para sua formação.

$\mathrm{O}$ quarto tipo de atividade mais realizada pelos egressos foram os estágios extracurriculares, com 6,3\% ( $\mathrm{n}=405)$, demonstrando preocupação com o desenvolvimento de habili- dades clínicas e cirúrgicas, bem como a necessidade de já buscar conhecer o mercado de trabalho, quer na esfera pública, quer na esfera privada. Esta procura por espaços de prática médica reflete as dificuldades do curso em ofertar estágio curricular e/ou atividades práticas em unidades de saúde, principalmente durante as quatro primeiras séries, pois o curso da UEFS não possui serviços próprios, precisando negociar com as esferas municipal e estadual os campos de práticas.

Vieira et al..$^{20}$ avaliaram estudantes de Medicina quanto ao grau de envolvimento e às motivações que levam estudantes do primeiro ao quarto ano de Medicina de uma faculdade do interior paulista a participar de atividades extracurriculares e concluíram que a maioria realiza atividades relativas à prática médica. A questão do estágio extracurricular como fonte de percepção financeira pelo estudante não emergiu dos dados desta pesquisa. Entretanto, as atividades remuneradas podem ser, dependendo das necessidades do estudante, um importante fator motivador, conforme relata o trabalho de Zimmer et al. ${ }^{18}$, no qual, numa amostra de 165 estudantes de um curso médico, 21,3\% eram motivados pela remuneração financeira para realizar atividades extracurriculares.

Ainda com relação ao estágio extracurricular, a comissão de avaliação adota como critério aceitar os certificados provenientes de unidades de saúde vinculadas ao SUS e, no caso de serviços privados, apenas daqueles cujo responsável técnico seja docente do curso. Esses critérios foram adotados com a

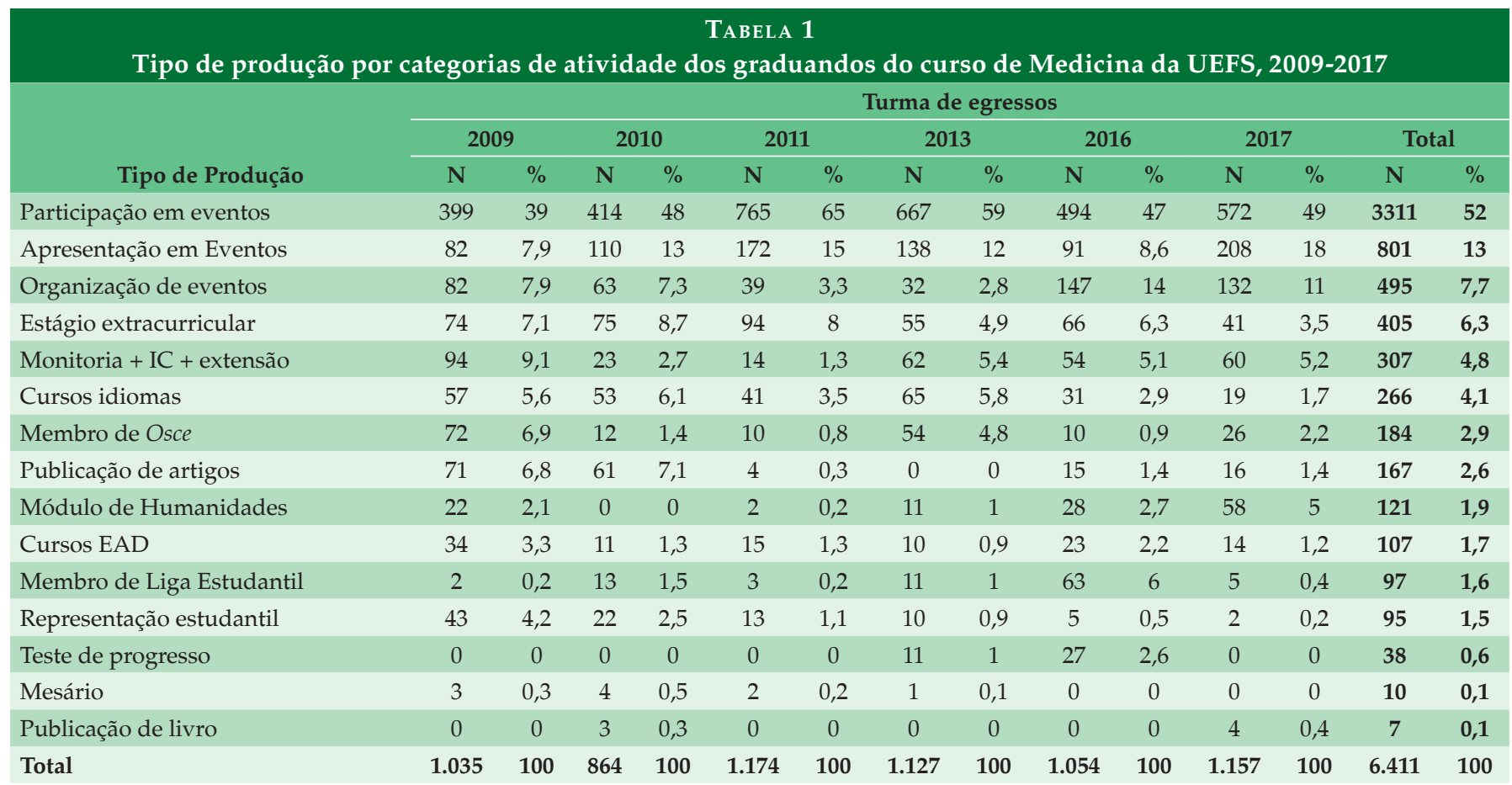


finalidade de direcionar os estudantes para locais que colaborem com a sua formação médica.

A participação dos estudantes em atividades de monitoria + iniciação científica + extensão ficou em quinto lugar, com $4,8 \%$ ( $\mathrm{n}=307)$. Estas são atividades intimamente associadas ao tripé universitário de ensino, pesquisa e extensão, e, portanto, deveriam ser valorizadas pelos estudantes. Embora esta categoria tenha ocupado o quinto lugar, foi pouco expressivo o percentual encontrado. Acredita-se que esse fato possa acontecer muito provavelmente devido à grande carga horária de atividades de ensino por conta da metodologia do curso, o que dificulta ao estudante dispor de 12 horas semanais para se dedicar a essas atividades, conforme exigência dos editais de bolsa. Apesar disso, observou-se uma razoável produção de artigos científicos $(2,6 \%-n=167)$, com a média de 0,93 artigo por aluno, com ênfase principalmente nas duas primeiras turmas formadas, por conta do momento de instalação do curso. Recentemente, tivemos uma retomada desta produção científica por conta da criação de ligas acadêmicas e da inserção de estudantes em núcleos de pesquisa vinculados ao Programa de Pós-Graduação em Saúde Coletiva (PPGSC).

Um importante elemento na formação médica atual aparece em sexto lugar - o acesso a cursos de idiomas -, com 4,1\% ( $n=266)$, ressaltando a preocupação dos estudantes com a sua formação pessoal e científica. Vale enfatizar que os periódicos com melhores conceitos são editados em língua estrangeira. Chamou-nos a atenção também o grande número de certificados de participação nas Osce (Objective Structured Clinical Examination), que ficou em sétimo lugar, com 2,9\% ( $\mathrm{n}=184)$. Esse tipo de avaliação de habilidades práticas é muito utilizado na metodologia APB, sinalizando que os estudantes se envolvem nas atividades do curso, exercendo seu protagonismo na construção do conhecimento.

No caso específico do curso de Medicina da UEFS, o parecer da comissão de avaliação ainda não permite o aproveitamento de carga horária de atividades esportivas e culturais. Este fato vai de encontro ao preconizado pelo MEC, que estimula a diversidade como elemento essencial para o processo de formação social e profissional ${ }^{11}$. A omissão sobre essas atividades prejudica os estudantes, principalmente após a criação da "Atlética de Medicina da UEFS", que estimula a prática de atividade física entre os estudantes e a participação em competições, a exemplo do "Intermed", que acontece anualmente, congregando diversos cursos de Medicina da Bahia e sendo também um momento de confraternização. Neste sentido, ressaltamos a experiência da Faculdade de Medicina de Ribeirão Preto, que inclui como atividades complementares as práticas esportivas (Associação Atlética Acadêmica), a realização de atividades artísticas (dança, teatro e fotografia), a participação na comissão de formatura e a assistência à população ${ }^{20}$.

No Brasil, apesar de vivenciarmos um momento de grandes mudanças no contexto da educação médica, com ênfase na formação de generalistas, ainda persistem características do modelo flexneriano de formação profissional, ocasionando uma grande valorização precoce das especialidades médicas durante a graduação. Este modelo leva os estudantes a buscar atividades na área do conhecimento que pretendem seguir na residência médica, construindo uma compreensão por vezes equivocada sobre a importância da composição de um bom currículo direcionado à especialidade pretendida.

A Tabela 2 apresenta as especialidades médicas e áreas do conhecimento mais procuradas pelos estudantes da UEFS nas duas categorias de atividades complementares mais prevalentes: participação + apresentação + organização em eventos e estágio extracurricular. Destacamos também a produção científica, por ser uma modalidade de atividade complementar em que o protagonismo do estudante é evidente.

Quanto à participação + apresentação + organização em eventos científicos, observa-se predomínio da Cardiologia, com 16,6\% ( $n=694)$ dos certificados apresentados, muito provavelmente por conta da existência de uma entidade de classe dessa especialidade muito atuante no município e do Grupo de Estudos em Cardiologia e Oncologia (Gecon), que agrega muitos estudantes como bolsistas e/ou voluntários em atividades de pesquisa. A Infectologia foi a segunda especialidade mais procurada, com 5,3\% $(n=222)$, pelo fato de o município de Feira de Santana ter tido um surto epidêmico de febre chikungunya em 2014 e outro de Zika vírus em 2015, ocasionando um aumento de eventos sobre as arboviroses. Pediatria, com 5,1\% ( $n=212)$, Pneumologia, com 4,9\% $(n=205)$ e Urgência e Emergência, com 4,8\% (n = 201), também foram especialidades muito procuradas pelos estudantes. Acredita-se que a quantidade de eventos desenvolvidos pelas sociedades de cada especialidade, bem como atividades promovidas por ligas acadêmicas e comissões de formatura, com frequência relacionados a essas áreas, são fatos que legitimam os resultados encontrados. Na categoria outros, com $46,7 \%(n=1.946)$, estão as demais 33 especialidades/áreas de conhecimento, conforme a nomenclatura do CFM ${ }^{14}$ e da Capes $^{15}$.

Quando analisamos as possibilidades de estágios extracurriculares, verificamos o predomínio das atividades em Urgência e Emergência, com 38,5\% (n = 101), e Cirurgia, com $12,2 \%(n=32)$, situação que indica que os estudantes buscam os plantões com o objetivo de aprimorar as habilidades clínicas e cirúrgicas relativas aos procedimentos médicos. Em terceiro lugar, com $11,0 \%(n=29)$, ficaram os estágios na área de 


\begin{tabular}{|c|c|c|c|c|c|c|}
\hline \multicolumn{7}{|c|}{$\begin{array}{c}\text { TABELA } 2 \\
\text { Especialidades médicas/áreas do conhecimento mais procuradas pelos } \\
\text { graduandos do curso de Medicina da UEFS, 2009-2017 }\end{array}$} \\
\hline \multirow{3}{*}{ Especialidades / áreas do conhecimento } & \multicolumn{6}{|c|}{ Tipo de atividade complementar } \\
\hline & \multicolumn{2}{|c|}{$\begin{array}{c}\text { Participação + apresentação + } \\
\text { organização em eventos }\end{array}$} & \multicolumn{2}{|c|}{ Produção científica } & \multicolumn{2}{|c|}{$\begin{array}{l}\text { Estágio } \\
\text { extracurricular }\end{array}$} \\
\hline & $\mathbf{N}$ & $\%$ & $\mathbf{N}$ & $\%$ & $\mathbf{N}$ & $\%$ \\
\hline Cardiologia & 694 & 16,6 & 23 & 17,8 & 3 & 1,1 \\
\hline Cirurgia & 82 & 2,0 & 0 & 0,0 & 32 & 12,2 \\
\hline Clínica médica & 37 & 0,9 & 0 & 0,0 & 14 & 5,3 \\
\hline Endocrinologia & 81 & 1,9 & 5 & 3,9 & 0 & 0,0 \\
\hline Ginecologia e obstetrícia & 120 & 2,9 & 4 & 3,1 & 8 & 3,0 \\
\hline Infectologia & 222 & 5,3 & 12 & 9,3 & 19 & 7,2 \\
\hline Medicina de família e comunidade & 150 & 3,6 & 13 & 10,1 & 0 & 0,0 \\
\hline Medicina intensiva & 123 & 2,9 & 8 & 6,2 & 22 & 8,4 \\
\hline Pediatria & 212 & 5,1 & 32 & 24,8 & 29 & 11,0 \\
\hline Pneumologia & 205 & 4,9 & 3 & 2,3 & 0 & 0,0 \\
\hline Saúde coletiva \& saúde pública & 101 & 2,4 & 19 & 14,7 & 0 & 0,0 \\
\hline Urgência e emergência & 201 & 4,8 & 2 & 1,6 & 101 & 38,5 \\
\hline Outros & 1.946 & 46,7 & 8 & 6,2 & 35 & 13,3 \\
\hline Total & 4.174 & 100 & 129 & 100 & 263 & 100 \\
\hline
\end{tabular}

Pediatria, quase todos realizados no Hospital da Criança, que é a referência estadual na região para esta especialidade. Por fim, com 8,4\% ( $\mathrm{n}=22)$, destacou-se a Medicina Intensiva, comprovando a preferência dos estudantes em aprimorar o conhecimento nas atividades hospitalares, de alta complexidade e voltadas à atenção individual, características do modelo flexneriano, que, apesar de todas as mudanças implementadas pelas DCN nos cursos de Medicina, ainda prevalece no imaginário do futuro médico, refletindo-se em suas escolhas para as atividades complementares.

A despeito dos esforços das reformulações curriculares realizadas por diversos cursos do País, inclusive a UEFS, e das medidas para fortalecer a formação do médico generalista, com enfoque na ABS, a partir da Medicina de Família e Comunidade e das ações em Saúde Coletiva, observa-se que os estágios em unidades de saúde da família não ocorreram em nenhuma turma. A respeito deste resultado, ficam algumas questões: será que existem falhas nos serviços municipais em ofertar essas vagas de estágio? Os estudantes da UEFS não estão motivados para estagiar nesta área de conhecimento? Os estudantes já se sentem contemplados com o conhecimento construído durante os quatro anos do módulo de Práticas de Integração Ensino, Serviço e Comunidade - Piesc (600 horas) e o internato de Saúde Coletiva/Saúde Mental (420 horas)? Estas são perguntas que precisam ser respondidas por outro estudo, pois o projeto político pedagógico do curso sustenta que, ao concluir a graduação, o egresso deve saber atuar dentro do SUS, respeitando os princípios de universalidade, integralidade e equidade que o fundamentam ${ }^{12}$, sendo que a ABS é a principal estratégia de capilaridade da atenção à saúde no País, tendo a Saúde da Família como sua principal estratégia ${ }^{21}$.

$\mathrm{O}$ acesso aos programas de residência médica é um referencial observado pelos estudantes no momento de escolher suas atividades complementares. No processo seletivo unificado de residência médica/Bahia 2019²2, do total de 746 vagas, foram oferecidas apenas 59 vagas $(7,9 \%)$ de Medicina de Família e Comunidade, para as áreas cirúrgicas foram 95 vagas (12,7\%) e para a Clínica Médica foram 123 vagas (16,4\%). Em termos de concorrência, a maior média foi de Otorrinolaringologia (15,0 candidato/vaga), seguida por Psiquiatria, com 12,6 candidato/vaga, e Oftalmologia, com 11,8 candidato/vaga; a procura por Medicina de Família e Comunidade foi de apenas 0,53 candidato/vaga ${ }^{22}$. Portanto, verifica-se maior número de vagas e concorrência em especialidades com densidade tecnológica e voltadas para procedimentos individuais e de grande complexidade, produto do modelo flexneriano, ainda hegemônico no exercício profissional da medicina.

Salientamos que as propostas de mudanças na graduação e residências médicas contidas no bojo do Programa Mais Médicos para o Brasil ${ }^{23}$ e nas DCN de 2014³, como oferecer um período da residência em Medicina Geral de Família e Comunidade e aumentar a carga horária em atenção básica 
durante o internato, podem estimular os estudantes a buscar, futuramente, atividades complementares nessas áreas de conhecimento.

Chaves et al. ${ }^{24}$ analisaram os critérios de avaliação curricular dos editais de programas de residência médica no Brasil e encontraram como itens mais bem pontuados: publicação de artigos científicos, presente em 97,6\% dos editais; em segundo lugar, monitorias (92,3\%), seguido de apresentação de resumos em congresso $(87,9 \%)$ e estágio em hospitais $(80,6 \%)$. Portanto, o colegiado do curso necessita discutir e orientar os estudantes na escolha das atividades complementares, articulando as aspirações individuais com as modalidades disponíveis.

As mudanças implementadas no processo de formação médica têm contribuído para a inserção de egressos em programas de pós-graduação stricto sensu, por isso analisamos também a relação entre produção científica e as especialidades médicas/áreas do conhecimento. Observa-se que a maioria dos estudantes que produziu publicações científicas estava inserida em núcleos de pesquisa pertencentes ao Programa de Pós-Graduação em Saúde Coletiva, prevalecendo a Pediatria, com 24,8\% ( $\mathrm{n}=32)$ dos artigos. Registre-se que dois núcleos do PPGSC têm professores da Pediatria como pesquisadores responsáveis. Em seguida, veio a Cardiologia, com 17,8\% (n = 23) dos artigos, provenientes do Gecon. Embora não tenham figurado na categoria estágio extracurricular, a Saúde Coletiva, com 14,7\% ( $\mathrm{n}=19$ ), e a Medicina de Família, com 10,1\% $(n=13)$, aparecem em terceiro e quarto lugares em produção científica, porém, se agrupadas, ficariam em primeiro lugar, empatadas com a Pediatria. Esse desempenho se explica por existir um grande número de professores envolvidos nos diversos núcleos de pesquisa do PPGSC atuando nas áreas de Planejamento e Gestão em Saúde, Epidemiologia e Formação Profissional em Saúde. O componente curricular Piesc também constituiu uma importante fonte de publicação, principalmente durante os quatro primeiros anos do curso. A despeito da participação de estudantes do curso de Medicina como bolsistas e voluntários nos núcleos de pesquisa, até o ano de 2018 nenhum estudante do curso ingressou no PPGSC.

O processo de contagem de carga horária adotado pela Comissão de Avaliação do Curso de Medicina da UEFS impõe critérios para o aproveitamento, bem como limites máximos para algumas categorias de atividade (Quadro 1). Por isso, existem perdas para os estudantes, que acabam cumprindo, ao longo do curso, muito mais que as 490 horas exigidas.

O Gráfico 1 expõe as cargas horárias apresentadas e as efetivamente aproveitadas pelos estudantes, nas categorias em que existe limite máximo, com base no parecer da comissão de avaliação.

Percebe-se que a maior perda acontece na categoria estágio extracurricular, em que o estudante perde cerca de $74 \%$ da carga horária apresentada. Isto acontece em razão dos critérios estabelecidos pela comissão de avaliação, que segue as normas estabelecidas pelos conselhos superiores da universidade ${ }^{25,26}$, pelas quais nesta categoria só se aproveitam no máximo 123

GRÁFICO 1

Carga horária perdida por categorias de atividades complementares com limite máximo de aproveitamento dos graduandos do curso de Medicina da UEFS, 2009-2017

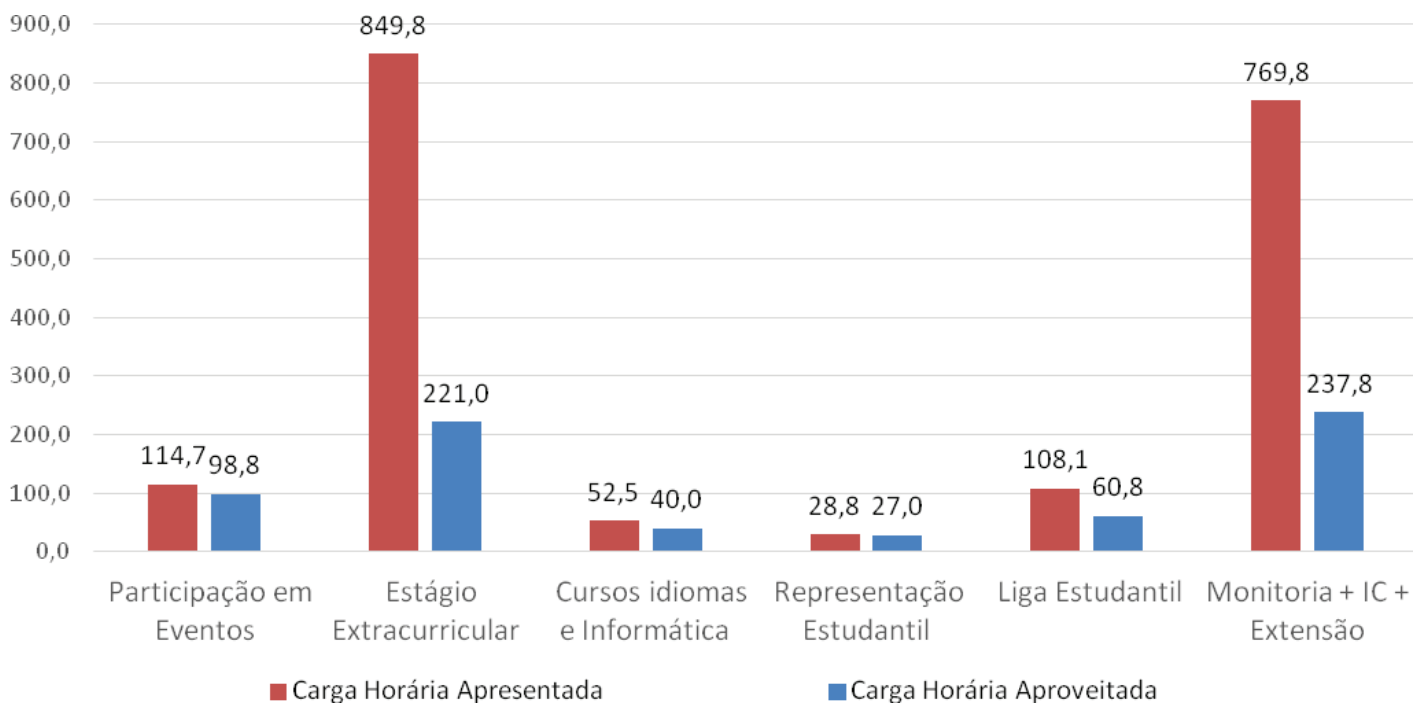


h/ano, até o máximo de 368 horas totais aproveitadas. Como a maioria dos estudantes realiza estágios extracurriculares em regimes de plantão nos fins de semana e férias, a maior parte dos certificados apresentados ultrapassava os limites estabelecidos, ocasionando grande perda de carga horária.

Situação semelhante ocorre com a categoria monitoria + iniciação científica + extensão, na qual há perdas de aproximadamente $63 \%$. Neste caso, a perda para os estudantes bolsistas é muito grande, uma vez que a carga horária anual da bolsa, seja ela de monitoria, iniciação científica ou extensão, é de 480 h/ano, sendo aproveitadas no máximo 123 h/ano. Para os estudantes voluntários, como não existe uma carga estabelecida a priori, as perdas foram menores.

Na categoria participação em eventos, a mais apresentada pelos estudantes, a perda foi reduzida, cerca de $14 \%$, reforçando ser uma boa opção de atividade complementar. Nas outras categorias analisadas, as perdas foram muito pequenas, não prejudicando os estudantes. É importante reduzir as perdas de carga horária ao mínimo possível, pois as obrigações teóricas e práticas do currículo mínimo são muito grandes, deixando pouco tempo para as atividades complementares. Segundo Tavares et al. ${ }^{5}$, os estudantes utilizam seus horários de refeições, fins de semana, férias, e, em muitos casos, é comum a superposição de compromissos curriculares com as atividades complementares, num claro malabarismo de horários, comprometendo os escassos momentos de repouso, lazer, atividade física e aquisição e ampliação de conhecimentos em áreas não médicas.

Cabe esclarecer que, segundo as resoluções do Conselho Superior de Ensino, Pesquisa e Extensão (Consepe) 54/200125 e $172 / 2010^{26}$, os limites estabelecidos para determinadas categorias ocorrem para induzir o estudante a buscar diversificar os tipos de atividades complementares e, dessa forma, ampliar seu leque de conhecimentos. Caso não existissem esses limites, os estudantes facilmente cumpririam a carga horária estabelecida com apenas uma categoria, conforme verificamos na graduação em Medicina, onde o estágio extracurricular teve a média de 849,8 h/estudante, e a monitoria + iniciação científica + extensão, a média de 647,8 h/estudante, muito acima das $490 \mathrm{~h}$ /estudante exigidas pelo curso.

Embora haja necessidade de diversificar os tipos de atividades complementares, conforme estabelecido pelo Consepe e referendado pelo colegiado do curso de Medicina da UEFS, acreditamos que existam perdas significativas em determinadas categorias, o que justifica uma discussão sobre a revisão desses limites, com a participação de estudantes e professores, num processo dialógico de aperfeiçoamento do Regimento das Atividades Complementares.
Atualmente, os estudantes entregam os certificados referentes às atividades complementares no sexto ano, às vésperas da formatura. Acreditamos que o Regimento das Atividades Complementares possa estabelecer a obrigatoriedade de entrega anual dos certificados. Assim, os membros da comissão de avaliação poderiam orientar cada estudante sobre as categorias em que ele ainda pode pontuar, reduzindo as perdas e diversificando as atividades realizadas.

\section{CONCLUSÃO}

Embora o curso de Medicina da UEFS tenha um projeto político pedagógico moderno, seguindo as atuais Diretrizes Curriculares Nacionais, com ênfase na formação de um médico generalista, voltado às necessidades do SUS e capacitado para atuar na ABS, percebe-se, por meio do perfil das atividades complementares, que os estudantes do curso preferem realizar atividades voltadas às especialidades médicas de maior complexidade, como também atividades que desenvolvam as habilidades de clínica e cirurgia, características do modelo flexneriano, ainda influente no processo de formação médica.

Além disso, a grande concentração das atividades complementares na categoria "participação em eventos" reflete a necessidade de orientar os estudantes para a diversificação dos cenários de práticas, tendo em vista a formação complementar. Assim, cabe ao colegiado do curso e ao corpo de professores incentivar a participação dos estudantes nas diversas atividades previstas pelo curso em seu regimento ${ }^{13}$, instigando-os a vivenciar diferentes experiências dentro e fora do ambiente universitário.

Os resultados deste estudo suscitam ainda a necessidade de discussão e revisão do Regimento de Atividades Complementares do Curso de Medicina da UEFS, além de subsidiar o colegiado do curso a implementar ações efetivas de orientação, acompanhamento, avaliação e ampliação das atividades complementares realizadas pelos estudantes dentro e fora do ambiente universitário. A intenção seria reduzir a grande disparidade entre carga horária apresentada e carga horária aproveitada em categorias de atividade importantes, como iniciação científica, bolsa monitoria, projetos de extensão e estágio extracurricular. A medida também permitirá a inclusão de mecanismo de aproveitamento de novas atividades, como participação em atividades culturais, esportivas e de voluntariado em instituições/eventos de amparo social.

Espera-se que este estudo possa contribuir para a educação médica, discutindo um tema por vezes esquecido na maioria dos cursos de graduação em Medicina. As atividades complementares não podem se limitar a uma atividade carto- 
rial de conferir certificados e contar carga horária, mas devem, sim, ser utilizadas pelos estudantes, sob orientação dos colegiados de curso, para complementar sua formação profissional e social.

\section{REFERÊNCIAS}

1. Campos FE, Aguiar RAT, Belisário SA. A formação Superior dos Profissionais de Saúde. In: Giovanella L, Escorel S, Lobato LVC, Noronha JC, Carvalho AI (orgs.). Políticas e Sistema de Saúde no Brasil. $2^{\text {a }}$ ed. Rio de Janeiro: editora Fiocruz, 2012. P. 885-910.

2. Brasil. Ministério da Educação. Resolução CNE/CES nº 4, Institui Diretrizes Curriculares Nacionais do Curso de Graduação em Medicina. Brasília: Ministério da Educação, 2001.

3. Brasil. Ministério da Educação. Resolução CNE/CES n⿳o 3, Institui Diretrizes Curriculares Nacionais do Curso de Graduação em Medicina e dá outras providências. Brasília: Ministério da Saúde, 2014.

4. Peres CM, Andrade AS, Garcia SB. Atividades extracurriculares: multiplicidade e diferenciação necessárias ao currículo. Rev. Bras. Educ. Med. 2007; 31(3):203-211.

5. Tavares AP, Ferreira RA, França EB, Fonseca Júnior CA, Lopes GC, Dantas NGT, et al. O "Currículo Paralelo" dos estudantes de medicina da Universidade Federal de Minas Gerais. Rev. Bras. Educ. Med.2007; 31(3):254-265.

6. Tavares CHF, Maia JA, Muniz MCH, Malta MV, Magalhães BRC, Thomaz ACP. O currículo paralelo dos estudantes da terceira série do curso médico da Universidade Federal de Alagoas. Rev. Bras. Educ. Med. 2007;31(3):245-253.

7. Alves AJ. A gênese, a constituição e a implementação da Escola de Medicina e Cirurgia de Uberlândia 1954 a 1978. Uberlândia-MG, 2013. 136 f. Tese Doutorado em Ciências Humanas, Universidade Federal de Uberlândia.

8. Maia JA. Metodologias Problematizadoras em currículos de graduação médicas. Rev. Bras. Educ. Med. 2014; 38(4):566-574.

9. De Benedetto MAC, Gallian DMC. Narrativas de estudantes de Medicina e Enfermagem: currículo oculto e desumanização em saúde. Interface. 2018; 22(67):1197-1207.

10. Brasil. Ministério da Educação. Resolução CNE/CES no 2, Dispõe sobre carga horária mínima e procedimentos relativos à integralização e duração dos cursos de graduação, bacharelados, na modalidade presencial. Brasília: Ministério da Educação, 2007.

11. Brasil. Portal do MEC/perguntas frequentes/atividades complementares.Disponível em: www.mec.gov.br, acesso 21 out 2018.
12. Universidade Estadual de Feira de Santana. Projeto Político Pedagógico do Curso de Medicina. Feira de Santana: Colegiado de Medicina/PROGRAD, 2015.

13. Universidade Estadual de Feira de Santana. Regimento das Atividades Complementares do curso de Medicina. Colegiado de Medicina, 2011.

14. Conselho Federal de Medicina. Resolução do Conselho Federal de Medicina-CFM n. ${ }^{\circ}$ 1666/2003. Dispõe sobre a nova redação do Anexo II da Resolução CFM nº 1.634/2002, que celebra o convênio de reconhecimento de especialidades médicas firmado entre o Conselho Federal de Medicina, Associação Médica Brasileira e a Comissão Nacional de Residência Médica. Brasília: Conselho Federal de Medicina, 2003

15. Coordenação de Aperfeiçoamento de Pessoal de Nível Superior. Tabela de Áreas do Conhecimento. Disponível em: www.capes.gov.br/avaliacao/instrumentos-de-apoio/ tabela-de-areas-do-conhecimento-avaliacao, acesso 03 jul 2018.

16. Haddad AE, Morita MC, Pierantoni CR, Brenelli SR, Passarella T, Campos FE. Formação de profissionais de saúde no Brasil: uma análise no período de 1991 a 2008. Rev. Saúde Pública. 2010; 44(4):383-393.

17. Instituto Nacional de Estudos e Pesquisas Educacionais Anísio Teixeira. Censo da Educação Superior - 2016. Disponível em: www.inep.gov.br, acesso 23 out 2018.

18. Zimmer LP, Hidalgo MPL, Rodrigues RO, Martins CD, Machado SR, Zimmer PM. Curriculo oficial e curriculo paralelo na faculdade de medicina da UFRGS. Rev. Bras. Educ. Med. 1993; 17(3):25-7.

19. Taquette SR, Costa-Macedo LM, Alvarenga FB. Currículo paralelo: uma realidade na formação dos estudantes de medicina da UERJ. Rev. Bras. Educ. Med. 2003; 27(3):171176.

20. Vieira E, Barbieri C, Vilela D, Ianhez Júnior E, Tomé F, Woida $\mathrm{F}$, et al. $\mathrm{O}$ que eles fazem depois da aula? As atividades extracurriculares dos alunos de ciências Médicas da FMRP-USP. Medicina (Ribeirão Preto. Online). 2004; 37(1/2):84-90.

21. Brasil. Ministério da Saúde. Portaria no 2.436, aprova a Política Nacional de Atenção Básica. Brasília: Ministério da Saúde, 2017.

22. Bahia. Processo Seletivo Unificado de Residência Médica/ Bahia 2019. Disponível em: www.strixeducação.com.br. Acesso em: 20 set. 2018.

23. Brasil. Presidência da República. Lei $n^{0}$ 12.871.Institui o Programa Mais Médicos, altera as Leis no 8.745 e no 6.932, e dá outras providências. Brasília: DOU, 2013. 
24. Chaves HL, Borges LB, Guimarães DC, Cavalcanti LPG. Vagas para residência médica no Brasil: Onde estão e o que é avaliado. Rev. Bras. Educ. Med. 2013; 37(4):557-565.

25. Universidade Estadual de Feira de Santana. Resolução CONSEPE n. 54.Regulamenta as Atividades Complementares para os Cursos de Graduação. Gabinete do Reitor, 2001.

26. Universidade Estadual de Feira de Santana. Resolução CONSEPE n. 172, atualiza o Regulamento das Atividades Complementares para os Cursos de Graduação. Gabinete do Reitor, 2010.

\section{CONTRIBUIÇÃO DOS AUTORES}

Marcelo Leandro Santana Cruz participou da concepção e delineamento da pesquisa, da coleta de dados, da análise dos dados, da redação e da revisão do artigo. Marcelo Torres Peixoto participou da concepção e delineamento da pesquisa, da coleta de dados, da análise dos dados, da redação e da revisão do artigo. Carlos Alberto Lima da Silva participou da coleta de dados, da análise dos dados, da redação e da revisão do artigo. Wanessa Galvão Damas participou da coleta de dados e da análise dos dados. Ana Beatriz Menezes de Oliveira participou da coleta de dados e da análise dos dados.

\section{CONFLITO DE INTERESSES}

Os autores declararam não haver conflito de interesses neste estudo.

\section{ENDEREÇO PARA CORRESPONDÊNCIA}

Marcelo Torres Peixoto

Rua Raul Leite, n. 990, ap. 903, Ed. Residencial da Vila, Vila Laura, Salvador-BA, CEP: 40270-010

E-mail: marcelotpeixoto@gmail.com 